\title{
Why the Body? Why Now?
}

\author{
Katherine Binhammer
}

Even a cursory glance at contemporary feminism, popular culture or the current debates in theory, will reveal a certain fixation on 'The Body.' The body - as materiality, as text, as performativity - seems to surface at every turn, appearing with such repetitive urgency that our concern with the body has become an obsession, a compulsion. Why this obsession now? Why the proliferation of books, films, and television shows centred on troubling, celebrating, liberating, and transforming the body? From plastic surgery to cross-dressing, from Judith Butler to Hollywood film, contemporary culture returns again and again to the body. As Carole Bynum asks, in the title of a recent article, "Why All the Fuss about the Body?" Why the body? Why now?

This recent engagement with corporeality, in part, signifies a new direction in feminist studies and a rethinking of the traditional relationship of sex to gender. Many feminists are no longer naïvely comfortable in the assumption of a sexed female body grounding feminist theory and practice, and have begun to question the concomitant concentration of feminism on gender - envisioned separately from sex - as the site for political intervention. Judith Butler notes that feminism has assumed the irreducible materiality of the sexed body, and even the strictest adherent of a social constructivist position on sex and gender will "concede' the undeniability of 'sex' or its 'materiality'" (10). The project of feminism's turn toward the body could be loosely circumscribed as the attempt to foreground this concession - to write, to think, or to act upon the effects of this presumed undeniable materiality. Is the material reality of the female body, in fact, irrefutably fixed and unchanging? And are all bodies equally irreducible?

Instead of interrogating what constitutes this undeniable materiality, Judith Butler, in Bodies that Matter, questions the discursive effects of this very assumption; she wonders whether an irreducible, fixed, female body will always be the necessary ground for feminist practice (29). She poses the question in the following way: 
...[T]he presumption of the material irreducibility of sex has seemed to ground and to authorize feminist epistemologies and ethics, as well as gendered analyses of various kinds. In an effort to displace the terms of this debate, I want to ask how and why 'materiality' has become a sign of irreducibility, that is, how it is that the materiality of sex is understood as that which only bears cultural constructions and, therefore, cannot be a construction?"

Whose interests are served, and what are the political effects, when feminist theory and practice begin from the presumption of a sexed body? My question is not posed as a censor. I do not mean to suggest a 'should' or 'should not,' or that it is 'wrong' to begin from this place. Rather, I am interested in thinking through how this assumption has framed the terms of feminist debates.

The assumed female body that permeates feminist history, I would argue, has often been the unspoken and concealed that has generated many divisions and disputes. The female body, while providing the starting point for feminists, has also been at the heart of most contentious issues: pornography, essentialism, and identity politics meet over the bodies they seek to liberate, specify and identify. Confrontations over the body have comprised the conceptual, textual, and political body of feminist debates. The Porn Wars of the 1970s and 80s were (and still are) largely a battle over the female body and how it enters representation. Is thebody conceived as victimized and in need of protection, here, meaning censorship? Or is it a free agent escaping the effects of power in its sexual representations? Troubling still, was the body in the Essentialism/ Contructivism debates. Does the female body have a specificity which produces necessary effects in texts, politics and subjectivity? Or is the female body a tabula rasa on to which culture writes a gendered script? The body remains at the centre of conflicts around identity politics. Does the body's race, class, or gender (to name only the privileged triumvirate), determine a subject's identity, an identity inaccessible to other bodies not similarly positioned? Or can we be, invent, perform, and imagine multiple bodily identities that we do not inhabit? Feminist debates about theory and practice often originate from a battle about the body: the body as a textual effect versus the 'real' material body in the streets. The assumption of an irreducible materiality often has had the effect of displacing and masking the terms of our debates: we presume agree- 
ment on irreducible materiality and battle over what it means, how it translates intoculture, or how it is used as a vehicleof oppression.

Thus, the current compulsion toward the body could be read as a corrective to this previous symptomatic blindness, a positive redressing of an earlier mistake. But we must be careful that in redressing this body (of work, of material, of woman), we do not repeat the history of dressing, cloaking, and covering, the female body. That is to say, we must not frame the question of the body in a way that supposes a fixed answer, an answer which would write onto the body another irreducible meaning transcending borders, histories, and locations. Take, for example, our current fascination with gender bending and cross-dressing. In addition to feminist theoretical interrogations, popular film has been captivated recently by the plot possibilities of cross-dressing; a fact which has led Marjorie Garber to enquire whether cross-dressing is "a phenomenon of our time?" (5). Films as diverse as The Crying Game, Tootsie, Mrs. Doubtfire, and To Wong Foo are all based on the play of the gendered body. This fascination with the troubling of gender could be interpreted as a positive liberation from the chains of a two-sex model of the body: if men can be women and women men, then women are no longer prisoners of their sex. But it also could be seen as an attempt to escape materiality in the grand tradition of Western philosophy's quest to overcome and master the body with the Cartesian mind. Rosi Braidotti registers caution with what she sees as the fantasy of being "beyond sex": "Blurring sexual difference by de-sexualizing masculinity precisely at the historical moment when the feminism of sexual difference is calling for the sexualization of practices...seems to me an extraordinarily perverse move" (157). Fixing the cross-dressed body as either integrally liberatory or as necessarily reactionary (a tendency all too commonly practiced) suggests to me a reinscription of the material, transcendent, body flowing across continents, cultures and classes. How and why we ask the question of the cross-dressed body, what answers we are looking for, when, where and by whom, seem crucially important - these questions will open up more possibilities than posit stable definitions of the cross-dressed body. But placing bodies at the crossroads of from where and at whom they speak will avoid dressing the body up with meanings that mask political stakes. The temporal question in my title-Why now? - is meant to register this locatedness and forestall a reading of this volume which seeks an answer to the ontological question 'What is the 
body?', such a reader would only be frustrated by these textual and visual bodies and their abilities to defy definitions. Instead, 'Why Now?' is meant to displace any quest for fixity onto the historical specificity of where, by whom, and which bodies are represented here, now, in these pages.

Theanswer to 'Why now?' in relation to this specificissue of Tessera has its own particular history. The theme of 'Bodies/Vesture/Ornament' was proposed many years ago when the specific material conditions of our own production - namely, the Canada Council - demanded a new long range plan to accompany our grant application. At that time(1993), a thematic volume on bodies in contemporary Canadian women's writing seemed like a developing topic in need of a publishing forum. And it seemed like a topic that would invite an expansion of Tessera's editorial focus on fiction theory to include the new editorial collective's interest in the relation of textuality to cultural studies. In the interim, much has been written, spoken and performed, on the body, a fact which, in addition to explaining why it solicited a larger number of contributions than any recent issue of the journal, or to suggesting a very active interpretativecommunity for this volume, also positions this issue within a series of ongoing and developing explorations.

Venturing into and opening up the question of the body that flows through the pages of this particular text we see that corporeality is not explored in isolation; bodies are here located by their relation to sexuality, textuality, gender, dress, memory, history, absence and transformation. Intersecting, overlapping, and contradicting, these relations are never represented as unitary or predetermined. The body that emerges from these pages, in the first instance, is not singular: there is no selfcontained body, only a series of bodies contaminating, and contaminated by, themselves and others. The contradiction of multiplicity in the singular body sets the stage for Nicole Brossard's reading of her own personal, bodily, history in, and of, her texts; for her the question is not what body but about the plurality of remembered bodies in the singularity, the solitude, of her own body: "Je me suis donc demandé combien de corps j'avais connus dans ma vie d'écriture."

Textual corporeality and the body of/in writing is figured in a variety of ways throughout this volume. Brossard, Janice Hladki, and Erin Soros, question both how language forms the body and how the body tries to escape and mask itself through language. In "Sentence," for 
example, Soros writes the body into the text by playing with the rules of the university essay. How does the university, Soros asks, subjectivize the body through the essay format? Hladki and Soros' texts force us to ask how the institutional rules of writing and speaking guarantee the authoritative body. And both pieces, through their own textual disruptions, seek to write the body into the classroom and the text.

The remembered bodies of Sheila Stewart, Sylvia Legris, Claudine Potvin, Wendy McGrath and Sandra Haar intersect to open, rather than foreclose, the connections and discontinuities between bodies and their families and histories. These writers place their heroines within a history - political, personal, phantasmatic, and familial - to locate where the body is now. The body, in this instance, is entered into through the traces of memory, reminding the reader that bodies converse with the past and live in a present. In Sandra Haar's poem, "words for Miriam," history (represented by the photograph of a cross-dressed female performer viewed in an exhibit on "100 years of Yiddish in Canada") compels the speaker to position her own body in the poem. Why is she so interested in knowing everything about the woman in the picture? What part of this female performer dressed as a man speaks to her own body that she dresses in a man's vintage dark suit?

Haar's vintage suit is only one of the numerous moments in this volume when the body encounters its coverings, meetings which reveal the various ways coverings constitute that which is covered. Olga Duhamel, Melanie Kolbeins, Sheri Rapp, Lisa Robertson, and Darlene Searcy read clothes or vestures for the signs and practices of our bodies. In these texts, clothes are not simply the external representation of an essential body underneath, nor are they a conscious performance of a preferred ontology. Rather, the relation of bodies to clothes is envisioned as a conversation of subjects and identities with their materialities. Not the putting on, but the taking off of clothes comprises the topic for Melanie Kolbeins' essay "Women, Stripping, Taking it On." Kolbeins 'takes on' feminist debates about stripping (the pro-sex argument in favour of women's agency versus the pro-censorship position that all strippers are victims) and argues against this either/or identification of the female stripper. Rather, she suggests the necessity of attending to the particular material conditions of each strippers' situation and allowing for a multiplicity of bodies, each taking on their own relation to taking off. 
Can we put on the body that we choose? Can we represent the body of our fantasies? These are some of the questions explored in a variety of ways: from Sylvie Bourassa's poetic exploration of the female body in Christian iconography to Eva Elias's narrative of a female scupltor's (un)successful efforts to form the body in stone, this volume also registers the limitations - diverse and never definitive - which bodies negotiate. Foregrounding the limits and boundaries of the body's possibilities can tell us much about where we are now. But while bodies may have limits, they are not envisioned as deterministic and confining. In fact, the very notion of a 'real body' is troubled by many writers here. The texts of Trish Salah, Olga Duhamel and Sandra Haar examine the question: How does our assumption of a real body (underneath clothes, with a real sex, revealing a true desire) constitute that very reality? Trish Salah poses the question "who is writing in the feminine on whose body" in "hir" piece, "when there are three." The transsexual body in this text complicates any reduction of bodies to two sexes as s/he opens up a space for us to examine the assumptions we bring to texts about the bodies behind them. What female body counts in feminist writing? How does the truth of Woman authorize the embodied text? These are questions-unanswered today - which Salah's text opens and which demand further debate.

What bodies are not represented? There are many missing from these pages. Interestingly, it is the visual artists in this volume who register the absences, gaps and the unrepresentable of corporeality. The visual is usually thought of as the site for fixing the female body, certainly it is referenced in those terms by the writers in the volume: for example, the pornographic photographer's gaze in Claudine Potvin or the male artist's paintbrush in Elias' "Stone Pit." But the visual artists here - Kati Campbell, Catherine Heard, Jeannie Thib, and Marlene Weston - resist the seduction of visual transparency in representing the body. On the cover are shoes which Weston has constructed by winding ribbon around her own feet, thus, using the body as a negative for the casting of this pair of unwearable shoe-shells. The body in this piece is marked precisely by its absence. Jeannie Thib's linocut patterns of fragments of classical drapery also invoke a body which seems to have disappeared. The jagged-toothed jaw standing in the place of the vagina in Catherine Heard's collage similarly works through negativity, as a visual pun disrupting the gynophobic myth of the vagina dentata. Campbell's installation includes a white christening gown being lowered down onto 
a tailor's dummy; it is evident that the dress is never going to fit. Campbell's installation can be read as a reflection upon the death of a daughter, and the allusion to something missing and replaced gives it a memorial solemnity. The bodies lost, missing, and absent, also speak and write into the flesh we see here and now.

Conversations and correspondence with collective members has helped me in "thinking through the body." I would especially like to thank Jennifer Henderson for her thoughtful analysis of the visual art.

\section{Works Cited}

Braidotti, Rosi. "Organs Without Bodies." differences: Life \& Death in Sexuality. 1 (Winter 1989): 147-161.

Butler, Judith. Bodies that Matter: On the Discursive Limits of "Sex". New York \& London: Routledge, 1993.

Bynum, Caroline. "Why All the Fuss about the Body? A Medievalist's Perspective." Critical Inquiry. 22 (Autumn 1995): 1-33.

Garber, Marjorie. Vested Interests: Cross-Dressing and Cultural Anxiety. New York \& London: Routledge, 1992. 